\title{
Pengaruh Jenis Mulsa dan Dosis Bokashi Terhadap Pertumbuhan Cabai Rawit (Capsicum frutescens L.)
}

\author{
Ahmad Raksun ${ }^{*}$, Mahrus ${ }^{1}$, dan I Gde Mertha ${ }^{1}$ \\ ${ }^{1}$ Program Studi Pendidikan Biologi, Fakultas Keguruan dan Ilmu Pendidikan Universitas Mataram, Mataram, Indonesia
}

DOI: $10.29303 /$ jppipa.v6i1.332

Citation: Raksun, A., Mahrus., Mertha, I, G. 2020. Pengaruh Jenis Mulsa dan Dosis Bokashi Terhadap Pertumbuhan Cabai Rawit (Capsicum frutescens L.). Jurnal Penelitian Pendidikan IPA (JPPIPA). 6(1). pp. 57-.62

\section{Article history}

Received: October $25^{\text {th }} 2019$

Revised: December $20^{\text {th }} 2019$

Accepted: December $24^{\text {th }} 2019$

*Ahmad Raksun: Program Studi Pendidikan Biologi, Fakultas Keguruan dan Ilmu Pendidikan Universitas Mataram, Mataram, Indonesia. Email:

ahmadunram@unram.ac.id

\begin{abstract}
This research is about the effect of mulch type and bokashi dose on the growth of chili. This study aims to determine: (1) the effect of mulch type on the growth of chili, (2) the effect of bokashi dose on the growth of chili, (3) the effect of the interaction of mulch type and bokashi dose on the growth of chili. This research used factorial design consisting of 2 factors. The first factor is the type of mulch which consists of 3 types of mulch namely black silver plastic mulch, rice straw mulch and dry leaf mulch. The second factor is the dose of bokashi which consists of 6 levels, namely: $\mathrm{Po}=$ without giving bokashi (control), $\mathrm{P}_{1}=$ giving $0.4 \mathrm{~kg}$ bokashi, $\mathrm{P}_{2}=$ giving $0.8 \mathrm{~kg}$ bokashi, $\mathrm{P}_{3}=$ giving $1.2 \mathrm{~kg}$ of bokashi, $\mathrm{P}_{4}=$ giving $1.6 \mathrm{~kg}$ of bokashi and $\mathrm{P}_{5}=$ giving $2.0 \mathrm{~kg}$ of bokashi. Growth parameters measured were stem height, leaf blade length, leaf blade width and wet weight of chili stems. Data analysis was performed by analysis of variance. The results showed that: (1) mulch type significantly affected stem height, stem wet weight, leaf blade length and leaf blade width, silver black plastic mulch gave better results than other mulches, (2) The dose of organic fertilizer significantly affected height stem, stem wet weight and leaf blade length but not significantly affect leaf blade width, (3) interaction of mulch type and bokashi dose did not significantly affect stem height, stem weight, stem length, leaf blade length and leaf blade width.
\end{abstract}

Keywords: bokashi; growth of chili; mulch

Abstrak: Penelitian ini tentang pengaruh jenis mulsa dan dosis bokashi terhadap pertumbuhan cabai rawit. Penelitian ini bertujuan untuk mengetahui: (1) pengaruh jenis mulsa terhadap pertumbuhan cabai rawit, (2) pengaruh dosis bokashi terhadap pertumbuhan cabai rawit, (3) pengaruh interaksi jenis mulsa dan dosis bokashi terhadap pertumbuhan cabai rawit. Dalam penelitian ini digunakan rancangan faktorial yang terdiri atas 2 faktor. Faktor pertama adalah jenis mulsa yang terdiri atas 3 macam mulsa yaitu mulsa plastik hitam perak, mulsa jerami padi dan mulsa daun-daun kering. Faktor kedua adalah dosis bokashi yang terdiri atas 6 level yaitu: $\mathrm{P}_{\mathrm{o}}=$ tampa pemberian bokashi (kontrol), $\mathrm{P}_{1}=$ pemberian $0,4 \mathrm{~kg}$ bokashi, $\mathrm{P}_{2}=$ pemberian $0,8 \mathrm{~kg}$ bokashi, $\mathrm{P}_{3}=$ pemberian $1,2 \mathrm{~kg}$ bokashi, $\mathrm{P}_{4}=$ pemberian $1,6 \mathrm{~kg}$ bokashi dan $\mathrm{P}_{5}=$ pemberian $2,0 \mathrm{~kg}$ bokashi. Parameter pertumbuhan yang diukur adalah tinggi batang, panjang helaian daun, lebar helaian daun dan berat basah batang cabai rawit. Analisis data dilakukan dengan analisis sidik ragam. Hasil penelitian menunjukkan bahwa: (1) jenis mulsa berpengaruh nyata terhadap tinggi batang, berat basah batang, panjang helaian daun dan lebar helaian daun, mulsa plastik hitam perak memberikan hasil yang lebih baik dari mulsa lainnya (2) Dosis pupuk organik berpengaruh nyata terhadap tinggi batang, berat basah batang dan panjang helaian daun tetapi tidak berpengaruh nyata terhadap lebar helaian daun, (3) interaksi jenis mulsa dan dosis bokashi tidak berpengaruh nyata terhadap tinggi batang, berat basag batang, panjang helaian daun dan lebar helaian daun

Kata kunci: bokashi, mulsa. pertumuhan cabai rawit 


\section{Pendahuluan}

Pemupukan tanaman merupakan salah satu upaya yang dapat dilakukan untuk meningkatkan pertumbuhan tanaman. Pemupukan tanaman yang sering dilakukan petani adalah dengan menggunakan pupuk sintetik. Zulkarnain (2014) menjelaskan bahwa aplikasi input kimiawi yang berupa pupuk dan festisida sintetik dengan dosis tinggi tidak hanya berpengaruh menurunkan tingkat kesuburan tanah, tetapi juga mengakibatkan merosotnya keanekaragaman hayati, meningkatnya serangan hama dan penyakit, timbulnya hama resisten dan berkembangnya organisme parasit. Oleh karena itu diperlukan alternatif penggunaan pupuk yang ramah lingkungan.

Salah satu cara pemupukan ramah lingkungan yang dapat dilakukan adalah pemupukan tanaman dengan menggunakan bokashi. Hasil penelitian yang dilakaukan oleh Tufalia, et al., (2014) menunjukkan bahwa aplikasi pupuk bokashi kotoran sapi dengan dosis yang berkisar antara 5-7,5 per hektar memberikan pengaruh yang lebih baik terhadap padi sawah varietas konawe yang ditanam pada sawah ultisol di Desa Puosu Jaya. Raksun dan Mertha (2018) menyimpulkan bahwa pemberian bokashi pada lahan pertanian Desa Montong Are dapat meningkatkan produksi terong ungu. Pemberian bokashi berpengaruh nyata terhadap produsi padi (Raksun, 2018). Pemberian berbagai jenis bokashi memberikan pengaruh yang sangat nyata terhadap pertumbuhan dan hasil jagung manis (Mulyanti, et al.,, 2015). Aplikashi pupuk organik bokashi berpengaruh nyata terhadap perumbuhan dan hasil panen terong hijau (Raksun, et al., 2019).

Selain ketersediaan unsur hara dalam tanah, temperatur tanah, kelembaban tanah dan adanya gulma juga merupakan faktor yang berpengaruh terhadap pertumbuhan tanaman. Pemeliharaan temperatur dan kelembaban tanah dan pengedalian gulma dapat dilakukan dengan aplikasi mulsa pada lahan pertanian. Mulyatri (2003) menjelaskan bahwa aplikasi mulsa merupakan salah satu upaya menekan pertumbuhan gulma, memodifikasi keseimbangan air, suhu dan kelembaban tanah serta menciptakan kondisi yang sesuai bagi tanaman, sehingga tanaman dapat tumbuh dan berkembang dengan baik.

Berdasarkan uraian di atas maka dilakuan penelitian tentang pengaruh jenis mulsa dan dosis bokashi terhadap pertumbuhan cabai rawit. Tujuan dilaksanakannya penelitian ini adalah untuk mengetahui (1). Pengaruh jenis mulsa terhadap pertumbuhan cabai rawit, (2) pengaruh dosis bokashi terhadap pertumbuhan cabai rawit, (3) pengaruh interaksi jenis mulsa dan dosis bokashi terhadap pertumbuhan cabai rawit.

\section{Metode}

Penelitian ini dilaksanakan mulai bulan April sampai dengan September 2019 di Desa Bajur Kecamatan Labuapi Kabupaten Lombok Barat Propinsi Nusa Tenggara Barat. Bahan-bahan yang digunakan adalah kotoran kuda, timbangan, dedak halus, karung goni, karung nilon, sekam, effective microorganism 4, gula pasir, benih cabai rawit, pot plastik, mulsa plastik, mulsa jerami padi, mulsa daundaun kering, ajir bambu, insektisida, pagar bambu, plastik transparan dan air. Selanjutnya alat-alat yang digunakan adalah gelas ukur, cangkul, parang, sendok, ember plastik, timbangan, alat tulis menulis, gunting, mesin pompa air dan hand sprayer. Tahapan pelaksanaan penelitian: (1) pembuatan bokashi, (2) pemberian bokashi pada bedengan lahan pertanian, (3) pemasangan mulsa pada bedengan lahan, (4) penanaman bibit cabai rawit, (5) pengukuran paremeter penelitian, dan (6) analisis data.

Penelitian ini menggunakan rancangan faktorial yang terdiri atas dua faktor. Faktor pertama adalah jenis mulsa yang terdiri atas tiga macam mulsa yaitu mulsa plastik hitam perak $\left(\mathrm{M}_{1}\right)$, mulsa jerami padi $\left(\mathrm{M}_{2}\right)$ dan mulsa daun-daun kering $\left(\mathrm{M}_{3}\right)$. Faktor kedua adalah dosis pupuk organik yang terdiri atas enam level yaitu: $B_{0}=$ tampa pemberian bokashi (kontrol), $\mathrm{B}_{1}=$ pemberian $0,4 \mathrm{~kg}$ bokashi $/ 1 \mathrm{~m}^{2}$ lahan pertanian, $\mathrm{B}_{2}=$ pemberian $0,8 \mathrm{~kg}$ bokashi $/ 1 \mathrm{~m}^{2}$ lahan pertanian, $B_{3}=$ pemberian $1,2 \mathrm{~kg}$ bokashi $/ 1 \mathrm{~m}^{2}$ lahan pertanian, $\mathrm{B}_{4}=$ pemberian $1,6 \mathrm{~kg}$ bokashi $/ 1 \mathrm{~m}^{2}$ lahan pertanian,, $\mathrm{B}_{5}=$ pemberian $2,0 \mathrm{~kg}$ bokashi $/ 1 \mathrm{~m}^{2}$ lahan pertanian. Aplikasi bokashi sesuai dosis perlakuan dilakukan 32 hari sebelum tanam dan pemasangan mulsa dilakukan dua hari sebelum tanam. Parameter pertumbuhan yang diukur adalah tinggi batang, panjang helaian daun, lebar helaian daun dan berat basah batang. Pengukuran tinggi batang dilakukan pada saat tanaman berumur 60 hari, pengukuran panjang dan lebar helaian daun dilakukan pada saat tanaman berumur 40 hari dan pengukuran berat basah batang dilakukan pada saat tanaman berumur 150 hari. Data penelitian dianalisis dengan analisis sidik ragam (Gomez dan Gomez, 1995).

\section{Hasil dan Pembahasan}

Data hasil pengukuran parameter pertumbuhan tanaman cabai rawit adalah sebagai berikut: 
Tabel 1. Rerata Tinggi Batang Cabai Rawit akibat Perbedaan Jenis Mulsa dan Dosis Pupuk Organik

\begin{tabular}{llllll}
\hline Perlakuan & Tinggi Batang $(\mathbf{c m})$ & Perlakuan & Tinggi Batang $(\mathbf{c m})$ & Perlakuan & Tinggi Batang $(\mathbf{c m})$ \\
\hline $\mathrm{M}_{1} \mathrm{~B}_{0}$ & 52 & $\mathrm{M}_{2} \mathrm{~B}_{0}$ & 46 & $\mathrm{M}_{3} \mathrm{~B}_{0}$ & 46 \\
$\mathrm{M}_{1} \mathrm{~B}_{1}$ & 56 & $\mathrm{M}_{2} \mathrm{~B}_{1}$ & 48 & $\mathrm{M}_{3} \mathrm{~B}_{1}$ & 49 \\
$\mathrm{M}_{1} \mathrm{~B}_{2}$ & 58 & $\mathrm{M}_{2} \mathrm{~B}_{2}$ & 52 & $\mathrm{M}_{3} \mathrm{~B}_{2}$ & 51 \\
$\mathrm{M}_{1} \mathrm{~B}_{3}$ & 60 & $\mathrm{M}_{2} \mathrm{~B}_{3}$ & 54 & $\mathrm{M}_{3} \mathrm{~B}_{3}$ & 53 \\
$\mathrm{M}_{1} \mathrm{~B}_{4}$ & 61 & $\mathrm{M}_{2} \mathrm{~B}_{4}$ & 57 & $\mathrm{M}_{3} \mathrm{~B}_{4}$ & 56 \\
$\mathrm{M}_{1} \mathrm{~B}_{5}$ & 63 & $\mathrm{M}_{2} \mathrm{~B}_{5}$ & 58 & $\mathrm{M}_{3} \mathrm{~B}_{5}$ & 58 \\
\hline
\end{tabular}

Data pada Tabel 1 menunjukkan bahwa rerata tinggi batang cabai rawit tertinggi adalah $63 \mathrm{~cm}$ terdapat pada perlakuan $\mathrm{M}_{1} \mathrm{~B}_{5}$ (perlakuan mulsa pelastik hitam perak dan $2,0 \mathrm{~kg}$ bokashi per $1 \mathrm{~m}^{2}$ lahan). Rerata tinggi cabai rawit terendah adalah $46 \mathrm{~cm}$ Tabel 2. Hasil Analisis Sidik Ragam Tinggi Batang Cabai Rawit Akibat Perbedaan Jenis Mulsa dan Dosis bokashi

\begin{tabular}{llllll}
\hline Sumber Keragaman & DB & JK & KT & F. hit & F. tabel (0,05) \\
\hline Ulangan & 2 & 12 & 6 & & \\
Pelakuan & 17 & 1308 & 76,9 & & \\
Jenis mulsa (M) & 2 & 433 & 216,5 & 34,72 & 3,28 \\
Bokashi (B) & 5 & 858 & 171,6 & 27,52 & 2,49 \\
M x B & 10 & 17 & 1,7 & 0,27 & 2,12 \\
Galat & 34 & 212 & 6,2 & & \\
Umum & 53 & 1532 & & & \\
\hline
\end{tabular}

Hasil analisis sidik ragam pada Tabel 2 menunjukkan bahwa perbedaan jenis mulsa berpengaruh nyata terhadap tinggi batang cabai rawit, perbedaan dosis bokashi berpengaruh nyata terhadap tinngi batang cabai rawit. interaksi antara jenis mulsa Tabel 3. Rerata Panjang Helaian Daun Cabai Rawit (mm) akibat Perbedaan Jenis Mulsa dan Dosis Bokashi

\begin{tabular}{llllll}
\hline Perlakuan & $\begin{array}{l}\text { Panjang Helaian Daun } \\
(\mathbf{m m})\end{array}$ & Perlakuan & $\begin{array}{l}\text { Panjang Helaian } \\
\text { Daun }(\mathbf{m m})\end{array}$ & Perlakuan & $\begin{array}{l}\text { Panjang Helaian } \\
\text { Daun }(\mathbf{m m})\end{array}$ \\
\hline $\mathrm{M}_{1} \mathrm{~B}_{0}$ & 101 & $\mathrm{M}_{2} \mathrm{~B}_{0}$ & 96 & $\mathrm{M}_{3} \mathrm{~B}_{0}$ & 95 \\
$\mathrm{M}_{1} \mathrm{~B}_{1}$ & 102 & $\mathrm{M}_{2} \mathrm{~B}_{1}$ & 98 & $\mathrm{M}_{3} \mathrm{~B}_{1}$ & 96 \\
$\mathrm{M}_{1} \mathrm{~B}_{2}$ & 104 & $\mathrm{M}_{2} \mathrm{~B}_{2}$ & 99 & $\mathrm{M}_{3} \mathrm{~B}_{2}$ & 98 \\
$\mathrm{M}_{1} \mathrm{~B}_{3}$ & 107 & $\mathrm{M}_{2} \mathrm{~B}_{3}$ & 101 & $\mathrm{M}_{3} \mathrm{~B}_{3}$ & 100 \\
$\mathrm{M}_{1} \mathrm{~B}_{4}$ & 109 & $\mathrm{M}_{2} \mathrm{~B}_{4}$ & 103 & $\mathrm{M}_{3} \mathrm{~B}_{4}$ & 102 \\
$\mathrm{M}_{1} \mathrm{~B}_{5}$ & 111 & $\mathrm{M}_{2} \mathrm{~B}_{5}$ & 105 & $\mathrm{M}_{3} \mathrm{~B}_{5}$ & 105 \\
\hline
\end{tabular}

Pada Tabel 3 dapat dilihat bahwa rerata panjang helaian daun cabai rawit tertinggi adalah $111 \mathrm{~mm}$ terdapat pada perlakuan $\mathrm{M}_{1} \mathrm{~B}_{5}$ (perlakuan mulsa pelastik hitam perak dan $2,0 \mathrm{~kg}$ bokashi per $1 \mathrm{~m}^{2}$ lahan). Panjang helaian daun terendah terdapat pada Tabel 4. Hasil Analisis Sidik Ragam Panjang Helaian Daun Cabai Rawit Akibat Perbedaan Jenis Mulsa dan Dosis Bokashi

\begin{tabular}{llllll}
\hline Sumber Keragaman & DB & JK & KT & F. hit & F. tabel (0,05) \\
\hline Ulangan & 2 & 5,3 & 2,65 & & \\
Perlakuan & 17 & 1035,3 & 60,9 & & \\
Jenis mulsa (M) & 2 & 417,3 & 208,65 & 31,86 & 3,28 \\
Bokashi (B) & 5 & 611,3 & 122,26 & 18,67 & 2,49 \\
M x B & 10 & 6,7 & 0,67 & 0,10 & 2,12 \\
Galat & 34 & 222,7 & 6,55 & & \\
Umum & 53 & 1263,3 & 23,84 & & \\
\hline
\end{tabular}

Pada Tabel 4 dapat dilihat bahwa perbedaan jenis mulsa berpengaruh nyata terhadap panjang helaian daun cabai rawit, perbedaan dosis bokashi terdapat pada perlakuan $\mathrm{M}_{2} \mathrm{~B}_{0}$ dan $\mathrm{M}_{3} \mathrm{~B}_{0}$. Hasil analisis sidik ragam pengaruh perlakuan bokashi terhadap tinggi batang cabai rawit terdapat pada Tabel 2

dan dosis bokashi tidak berpengaruh nyata terhadap tinggi batang cabai rawit. Selanjutnya data hasil pengukuran panjang helaian daun cabai rawit terdapat pada Tabel 3.

perlakuan $\mathrm{M}_{3} \mathrm{~B}_{0}$ (perlakuan mulsa daun-daun kering dan $0 \mathrm{~kg}$ bokashi). Hasil analisis sidik ragam pengaruh jenis mulsa dan dosis bokashi terhadap panjang helaian daun cabai rawit disajikan pada tabel berikut. berpengaruh nyata terhadap panjang helaian daun cabai rawit. Interaksi antara perbedaan jenis mulsa dan 
panjang helaian daun cabai rawit. Selanjutnya data hasil pengukuran lebar helaian daun cabai rawit

Tabel 5. Rerata Lebar Helaian Daun Cabai Rawit akibat Perbedaan Jenis Mulsa dan Dosis Bokashi

\begin{tabular}{llllll}
\hline Perlakuan & $\begin{array}{l}\text { Lebar Helaian Daun } \\
(\mathbf{m m})\end{array}$ & Perlakuan & $\begin{array}{l}\text { Lebar Helaian } \\
\text { Daun }(\mathbf{m m})\end{array}$ & Perlakuan & $\begin{array}{l}\text { Lebar Helaian } \\
\text { Daun }(\mathbf{m m})\end{array}$ \\
\hline $\mathrm{M}_{1} \mathrm{~B}_{0}$ & 55 & $\mathrm{M}_{2} \mathrm{~B}_{0}$ & 51 & $\mathrm{M}_{3} \mathrm{~B}_{0}$ & 50 \\
$\mathrm{M}_{1} \mathrm{~B}_{1}$ & 55 & $\mathrm{M}_{2} \mathrm{~B}_{1}$ & 51 & $\mathrm{M}_{3} \mathrm{~B}_{1}$ & 51 \\
$\mathrm{M}_{1} \mathrm{~B}_{2}$ & 56 & $\mathrm{M}_{2} \mathrm{~B}_{2}$ & 52 & $\mathrm{M}_{3} \mathrm{~B}_{2}$ & 50 \\
$\mathrm{M}_{1} \mathrm{~B}_{3}$ & 55 & $\mathrm{M}_{2} \mathrm{~B}_{3}$ & 52 & $\mathrm{M}_{3} \mathrm{~B}_{3}$ & 51 \\
$\mathrm{M}_{1} \mathrm{~B}_{4}$ & 57 & $\mathrm{M}_{2} \mathrm{~B}_{4}$ & 53 & $\mathrm{M}_{3} \mathrm{~B}_{4}$ & 52 \\
$\mathrm{M}_{1} \mathrm{~B}_{5}$ & 57 & $\mathrm{M}_{2} \mathrm{~B}_{5}$ & 53 & $\mathrm{M}_{3} \mathrm{~B}_{5}$ & 52 \\
\hline
\end{tabular}

Hasil analisis sidik ragam pada Tabel 5 menunjukkan bahwa perbedaan jenis mulsa berpengaruh nyata terhadap lebar helaian daun tanaman cabai rawit, perbedaan dosis bokashi tidak berpengaruh nyata terhadap lebar helaian daun cabai rawit. Interaksi antara perbedaan jenis mulsa dan dosis bokashi tidak berpengaruh nyata terhadap lebar helaian daun cabai rawit.

Tabel 6. Hasil Analisis Sidik Ragam Lebar Helaian Daun Cabai Rawit Akibat Perbedaan Jenis Mulsa dan Dosis Bokashi

\begin{tabular}{llllll}
\hline Sumber Keragaman & DB & JK & KT & F. hit & F. tabel (0,05) \\
\hline Ulangan & 2 & 4 & 2 & & \\
Perlakuan & 17 & 275,3 & 16,19 & & 3,28 \\
Jenis mulsa (M) & 2 & 240,3 & 120,15 & 25,86 & 2,49 \\
Bokashi (B) & 5 & 27,3 & 5,46 & 17 & 2,12 \\
M x B & 10 & 7,7 & 0,77 & 0,17 & \\
Galat & 34 & 158 & 4,65 & & \\
Umum & 53 & 437,3 & 8,25 & & \\
\hline
\end{tabular}

Pada Tabel 7 dapat dilihat bahwa rerata berat basah batang cabai rawit teritnggi adalah 314 gram terdapat pada perlakuan $\mathrm{M}_{1} \mathrm{~B}_{5}$ (perlakuan mulsa Tabel 7. Rerata Berat Basah Batang Cabai Rawit (g) akibat

\begin{tabular}{llllll}
\hline Perlakuan & Berat Basah Batang $(\mathrm{g})$ & Perlakuan & Berat Basah Batang (g) & Perlakuan & Berat Basah Batang (g) \\
\hline $\mathrm{M}_{1} \mathrm{~B}_{0}$ & 298 & $\mathrm{M}_{2} \mathrm{~B}_{0}$ & 282 & $\mathrm{M}_{3} \mathrm{~B}_{0}$ & 280 \\
$\mathrm{M}_{1} \mathrm{~B}_{1}$ & 301 & $\mathrm{M}_{2} \mathrm{~B}_{1}$ & 285 & $\mathrm{M}_{3} \mathrm{~B}_{1}$ & 283 \\
$\mathrm{M}_{1} \mathrm{~B}_{2}$ & 305 & $\mathrm{M}_{2} \mathrm{~B}_{2}$ & 288 & $\mathrm{M}_{3} \mathrm{~B}_{2}$ & 287 \\
$\mathrm{M}_{1} \mathrm{~B}_{3}$ & 307 & $\mathrm{M}_{2} \mathrm{~B}_{3}$ & 291 & $\mathrm{M}_{3} \mathrm{~B}_{3}$ & 288 \\
$\mathrm{M}_{1} \mathrm{~B}_{4}$ & 310 & $\mathrm{M}_{2} \mathrm{~B}_{4}$ & 295 & $\mathrm{M}_{3} \mathrm{~B}_{4}$ & 293 \\
$\mathrm{M}_{1} \mathrm{~B}_{5}$ & 314 & $\mathrm{M}_{2} \mathrm{~B}_{5}$ & 298 & $\mathrm{M}_{3} \mathrm{~B}_{5}$ & 297 \\
\hline
\end{tabular}

Hasil analisis sidik ragam pada Tabel 7 menunjukkan bahwa perbedaan jenis mulsa berpengaruh nyata terhadap berat basah batang cabai rawit, perbedaan dosis bokashi berpengaruh nyata Tabel 8. Hasil Analisis Sidik Ragam Berat Basah Batang Cabai Rawit Akibat Perbedaan Jenis Mulsa dan Dosis Bokashi

\begin{tabular}{llllll}
\hline Sumber Keragaman & DB & JK & KT & F. hit & F. tabel (0,05) \\
\hline Ulangan & 2 & 44,3 & 22,15 & & \\
Perlakuan & 17 & 5113,3 & 300,78 & & \\
Jenis mulsa (M) & 2 & 3464,3 & 1732,15 & 26,60 & 3,28 \\
Bokashi (B) & 5 & 1641,3 & 328,26 & 5,04 & 2,49 \\
M x B & 10 & 7,64 & 0,76 & 0,01 & 2,12 \\
Galat & 34 & 2213,7 & 65,11 & & \\
Umum & 53 & 7371,3 & 139,8 & & \\
\hline
\end{tabular}

Hasil penelitian menunjukkan bahwa perbedaan jenis mulsa berpengaruh nyata terhadap pertumbuan cabai rawit. Penutupan bedengan lahan dengan mulsa pelastik hitam perak dan 2,0 $\mathrm{kg}$ bokashi per $1 \mathrm{~m}^{2}$ lahan). Berat basah batang cabai rawit terendah adalah 280 gram terdapat pada perlakuan $\mathrm{M}_{3} \mathrm{~B}_{0}$.

terhadap berata basah batang cabai rawit. interaksi antara jenis mulsa dan dosis bokashi tidak berpengaruh nyata terhadap berat basah batang cabai rawit. plastik hitam perak memberikan hasil yang lebih baik dari pada mulsa jerami padi dan mulsa daun daun kering. Hasil penelitian ini sejalan dengan hasil 
penelitian yang dilakukan oleh Kusumasiwi et, al., (2011) yang menyimpulkan bahwa penggunaan mulsa plastik hitam dan hitam perak nyata meningkatkan pertumbuhan dan hasil terung baik yang ditanam secara monokultur maupun tumpang sari dengan kangkung darat. Penggunaan mulsa plastik hitam perak dan jerami padi berpengaruh nyata pada beberapa variabel pengamatan, yaitu pada variabel tinggi tanaman, jumlah bunga, tingkat percabangan, jumlah buah panen, bobot buah panen, dan bobot buah total cabai merah (Aditya et al., 2013). Penggunaan mulsa plastik hitam perak menghasilkan tanaman bawang merah yang paling tinggi, jumlah daun dan jumlah umbi per rumpun yang paling banyak, serta berat segar umbi per rumpun dan berat umbi kering simpan per rumpun yang paling berat (Mahmudi, et al., 2017).

Data pada Tabel 1, 3 dan 6 menunjukkan bahwa cabai rawit yang tumbuh pada lahan percobaan yang ditutup mulsa daun-daun kering dan tanpa perlakuan bokashi memiliki rerata tinggi batang, panjang helaian daun daun, berat basah batang terendah (masingmasing adal $46 \mathrm{~cm}, 95 \mathrm{~mm}$ dan 280 gram). Selanjutnya pada lahan yang diberi perlakuan bokashi secara umum memiliki rerata panjang daun, lebar daun dan tinggi batang yang meningkat sejalan dengan meningkatnya dosis bokashi yang diberikan. Adanya pengaruh nyata dosis bokashi terhadap tinggi batang, panjang daun dan lebar cabai rawit dimungkinkan karena bahan organik yang dijadikan bahan baku pembuatan bokashi mengalami degradasi menjadi berbagai unsur hara terutama unsur hara $\mathrm{N}, \mathrm{S}$ dan $\mathrm{P}$. Hasil penelitian ini sejalan dengan hasil penelitian yang dilakukan oleh sejumlah peneliti lainnya. Perlakuan jenis dan dosis pupuk bokashi berpengaruh nyata pada panjang tanaman 24 hst dan berat buah total pertanaman kacang panjang. Berat total buah pada semua perlakuan berbeda nyata dengan kontrol. Dosis pupuk bokashi kotoran kuda maupun ayam yang terbaik untuk berat buah total pertanaman adalah 20 ton per hektar (Djunaedy, 2009). Aplikasi bokashi berpengaruh nyata terhadap pertumbuhan kacang panjang, (3) Interaksi jenis mulsa dan dosis bokashi tidak berpengaruh nyata terhadap pertumbuhan kacang panjang. (4) Dosis terbaik bokahi untuk pertumbuhan kacang pajang pada lahan pertanian Desa Sukarare adalah $1,8 \mathrm{~kg}$ bokashi untuk $1 \mathrm{~m}^{2}$ lahan pertanian (Raksun \& Japa, 2018). Pertumbuhan dan produksi tanaman tomat terbaik di jumpai pada perlakuan interaksi varietas Betavila F1 dan dosis pupuk bokashi kotoran ayam 15 ton/ha. Perlakuan varietas terbaik pada pertumbuhan dan produksi tanaman tomat di jumpai pada varietas Betavila. Perlakuan dosis pupuk bokashi kotoran ayam terbaik pada pertumbuhan dan produksi tanaman tomat di jumpai pada dosis pupuk 15 ton per hektar (Sahetapy, et al., 2017).
Rendahnya tinggi batang, panjang helaian daun dan berat basah batang cabai rawit pada media tanpa pemberian bokashi diduga disebabkan oleh kurang optimalnya ketersediaan berbagai unsur hara pada lahan pertanian Desa Bajur. Selanjutnya pemberian bokashi menyebabkan makin tersedianya unsur hara terutama sulfat dan nitrat yang berasal dari hasil penguraian kotoran kuda yang dijaikan bahan baku pembuatan bokashi.

\section{Kesimpulan}

Berdasarkan hasil analisis data dan
pembahasan pada penelitian ini maka dapat disimpulkan bahwa: (1) Perbedaan jenis mulsa berpengaruh nyata terhadap tinggi batang, panjang helaian daun, lebar helaian daun dan berat basah batang cabai rawit. (2) Perbedaan Dosis bokashi berpengaruh nyata terhadap tinggi batang, panjang helaian daun, dan berat basah batang tetapi tidak berpengaruh nyata terhadap lebar helaian daun cabai rawit. (3) Interaksi jenis mulsa dan dosis bokashi tidak berpengaruh nyata terhadap semua parameter pertumbuhan Cabai Rawit yang diukur.

\section{Ucapan Terimakasih}

Terimiakasih yang sebesar-besarnya kami sampaikan kepada Rektor dan Ketua LPPM Universitas Mataram yang telah memfasilitasi pelaksanaan penenelitian. Terimakasih juga kami sampaikan kepada semua pihak yang telah membantu pelaksanaan penelitian dan penyusunan artikel ini.

\section{References}

Aditya, A., Hendarto, K., Pangribuan, D., Hidayat, K. F. 2013. Pengaruh Penggunaan Mulsa Plastik Hitam Perak dan Jerami Padi terhadap Pertumbuhan dan Produksi Tanaman Cabai Merah (Capsicum annul L.) di Dataran Tinggi. Agrotek Tropika. 2(2): 147-152.

Djunaedy, A. 2009. Pengaruh Jenis dan Dosis Pupuk Bokashi terhadap Pertumbuhan dan Hasil Kacang Panjang (Vigna sinensis L). Agrovigor vol. 2 (1): 42 - 46

Gomez K. A. dan A. A. Gomez. 1995. Prosedur Statistik Untuk penelitian Pertanian Edisi 
Kedua Penerjemah: Endang Syamsudin dan Justika S. Baharsyah. Jakarta. UI Press

Kusumasiwi, A.W.P., Muhartini, S., Trisnowati, S. 2011. Pengaruh Warna Mulsa Plastik terhadap Pertumbuhan dan Hasil Terung (Solanum melongena L.) Tumpangsari dengan Kangkung Darat (Ipomoea reptans poir). Laporan Hasil Penelitian. Universitas Gadjah Mada. Yogyakarta.

Mahmudi, S., H. Rianto, H., Historiawati. 2017. Pegaruh Mulsa Plastik Hitam Perak dan Jarak Tanam pada Hasil bawang Merah (Allium cepa fa. ascalonicum, L.) varietas Biru Lancor. Vigor. Jurnal Ilmu Pertanian Tropika dan Subtropika. Vol. 2 (2): 60 - 62

Mulyatri. 2003. Dasar-Dasar Budidaya Pertanian. Jakarta. Bumi Aksara.

Mulyanti, S. S., Made, U. dan Wahyudi, I. Pengaruh Pemberian Berbagai Jenis Bokashi terhadap Pertumbuhan dan Hasil Jagung Manis (Zea mays Saccarata). Agrotekbis Vol 3(5): 592 $-601$

Raksun, A. 2018. Pengaruh Bokashi Terhadap Produksi Padi (Oryza sativa L). Jurnal
Penelitian Pendidikan IPA. Vol. 4 (1): 64 67

Raksun, A. dan Mertha, I. G. 2018. Pengaruh Bokashi terhadap Produksi Terong Ungu (Solanum melongena L). Biologi Tropis. Vol. 18 (1): $21-26$

Raksun, A dan Japa, L. 2018. Pengaruh Jenis Mulsa dan Dosis Bokashi terhadap Pertumbuhan Kacang Panjang. Jurnal Penelitian Pendidikan IPA. Vol. 5 (1) : $34-38$

Sahetapy, M. M., Pongoh, J., Tilaar, W. 2017. Analisis Pengaruh aBeberapa Dosis Pupuk Bokashi Kotoran Ayam terhadap Pertumbuhan dan Produksi Tiga Varietas Tomat (Solanum lycopersicum L.) Di Desa Airmadidi. Agri-SosioEkonomi Unsrat. Vol. 13 (2): $70-82$

Zulkarnain. H. 2014. Dasar-Dasar Hortikultura. Bumi Aksara. Jakarta. 